\title{
Some affected variables of information needs occurrence of an information seeker: a comprehensive hypothetical model
}

The Authors

KARUNANAYEKE, K.G.D.A.

BA(Hons.)(Kelaniya), MLS(Colombo), Dip.Russ., ASSLA

Doctoral Student,

Graduate School of Library, Information Media Studies, University of Tsukuba, Japan

\section{NAGATA, HARUKI}

Professor of Library Science

Graduate School of Library, Information Media Studies, University of Tsukuba, Japan 
Abstract

Affected variables of information needs occurrence of an information seeker which discussed in this paper are an important research area of the user studies. This paper is drawn on literary reviews focusing, in particularly the information needs concepts, theories, and its affected variables which explored the cognitive metaphors and methods. Even though researchers reviewed a range of several existing published pieces of literature on the target topic, the main objective of this paper is to discuss the key concepts of information needs from different angles to unify the concept of information needs through a new dimension while designing a very comprehensive hypothetical model of information needs occurrences.

This paper found that information needs occurrences happen through a complex process of involving the individual's insufficient knowledge structure. The complexity arose due to two kind of basic variables such as cognitive and socio variables. The problem of insufficient knowledge became apparent when a variety of void areas were identified in the current state of knowledge. These voids were identified through cognitive environment. The cognitive variables were found as a set of features which expresses the individual's knowledge identity and capacity. This paper suggests that some specific cognitive factors such as skill factors, knowledge factors and psychological statuses of the overall intellectual power which affected with the insufficient needs. In this context, different avenues of information needs occurrences were discussed in order to identify the nature of the needs and the characteristics involved with that process. 


\section{Keywords}

Information needs, Information needs occurrence, Information seeking, Information seeking models

\section{Introduction}

Information providers and resources are in a process of rapid change in the field of Information Science. Users are also subject to constant change. In this paper, the user is considered as the person who has information needs and a willingness to search for that information, particularly from libraries. These changes were clearly visible and noticeable in the behavioral patterns of the users. The way the users search for their needs is the mode of access. This mode may be a direct search by the user or mediated by the librarian or the library system. Hence, identification of the nature of the information needs and the affected variables of those needs is a significant part of the professional role.

For the past few decades, the scope of this paper has attracted many researchers in the field of Library Science. It has attempted to describe the identification of the needs in hundreds of different contexts. Even though there is a considerable interest in the role of information needs, it has been decided to examine several voluminous studies in this paper in order to have a clear understanding of the affected variables and the basic stages of information needs occurrences and investigate those in different contexts to make a unified framework.

Firstly, this paper attempts to discuss the factors associated with the information needs of users in the field of information research and to analyze several of them from different angles to understand the nature of the information needs and its affected variables. Selected studies from the huge storage of information needs explored the cognitive metaphors and 
methods which are expected to be explicated through a hypothetical model as an outcome of this study.

Secondly, this paper suggests information needs is a void creator. It happens owing to the very complex and complicated situations of the current status of the knowledge areas of the individuals.

Thirdly, the proposed model attempts to show some trends in information needs while focusing some variables and characteristics on people's information needs from a socio-cognitive viewpoint.

\section{Significance of the study}

Lack of understanding the subtle differences of a user's information needs is one of the crucial problems for information providers. As a research, identifying the vague nature of the user's information needs is an important study. Well-understood user needs are essential in a society where we can see an explosion of information. In this respect, from time to time, studying the users' complexity of information needs has emerged as a current development in the field of library and information science research.

Understanding the users' needs through a study of that nature will pave the way to design either a new information system or ameliorate the existing systems in the interest of the users' perspectives.

From the point of view of researchers and information professionals (Librarians), it is extremely important to study these needs and their demands when planning effective information skills among the users and assessing the user needs in different situations. Moreover, information needs are not directly observable but are inferred from a cluster of actions. information seekers who perceive that their available knowledge is less than that they needed in a particular issue lead to the above - mentioned 
cluster of actions or the information seeking process. Basically, the studies which we are going to discuss in this paper present the information needs situations and the seeking role which is connected to it. But this paper examines the factors which represent only the information needs and offer a cross section of different approaches. However, information needs occurrences hypothetically considered as an unobservable phenomenon. Understanding the unseen differences existing between the users and the information needs is essential. The most significant aspect of this paper is to examine the several eminent studies to unify the concept of information needs and present a new dimension while designing a very comprehensive model.

\section{Definition of information needs}

Information needs is a quite complicated concept to explore. It has ambiguous meanings. Defining a real meaning is controversial. Some have different ideas and a variety of perspectives. Throughout our literary examination on information needs, some have focused on the nature of the information needs while others have focused on the level of perceptions. From our point of view, needs arise from very complex situations of the available knowledge of individuals. The recognition of existing degrees of the total intellectual levels will help to reduce the said complexity. But to identify the definition of information needs through other perspectives, Atkins' and Rowley's definitions were considered. They defined information needs as

"A function of extrinsic uncertainty produced by a perceived discrepancy between the individual's current level of certainty about important environmental object and a creation state he seeks to achieve" (Atkins, 1973. pp.206)

"A need is generally conceived as describing what an individual ought to have, for his work, edification, recreation etc. Pin pointing a need implies a 
value judgment; one person may regard a piece of information as vital, while another, in the same situation, may attain the same goal without it". (Rowley, 1978. pp.54)

The information needs considered throughout this paper as a request made by the user to a library for his information and occurrence refers to the ways and roots of how it begins and works. Even though there are several synonymous terms used in the field of information studies, to avoid the terminological confusion, this paper hypothesizes about needs from the nature of the total activities in which individuals are involved till the moment comes to search for the information.

\section{A closer look at information needs from different angles}

\section{Needs as an answer for the question negotiation}

It is obvious that the users of libraries either search for information by themselves or expect the help of the library staff. But most of the users are likely to find information on their own. There are a large number of users who do not ask a librarian for any assistance. When designing user centered information services, all libraries should have to develop a self help process. Even though the users go through librarians, it is vital to understand the levels of the information needs of the users. Four levels of information needs are identified as a process of questioning and negotiation of the users (Taylor, 1968). After the users have perceived information needs, they search for the information. The users' ways of information seeking are to discuss with colleagues and to search for literature. When they decide to use the library, in each step, factors such as awareness, availability, and ease of access and the capacity of the library may affect the users' information needs. Also, he identifies two kinds of needs of the user such as short term needs and long-term interests. Short term needs have immediate consumption while long term interest has contextual values. The long term interests may tend to proceed in a cluster of actions. 
According to him, there are four stages of information needs of the users. His basic concept of the needs is to find an answer.

Visceral needs. - Unexpressed (unconscious) needs for information. If the users have a feeling that they have no confidence in questioning about what they really want, such a situation is full of doubt and uncertainty. Conscious needs. - It is a conscious mental description or ambiguous and rambling statement. In this situation, the users are quite confident of their needs but the level of needs is unfocused, unrevealed and full of ambiguity. Even though it reflects some areas of the needs, it is full of articulation. For fulfilling the needs, consulting friends, advisers and teachers could be the solutions. Formalized needs. - Qualified and rational needs or constructed needs. In this stage the users know well about what they want, where it is and what to ask but do not know how to ask. Compromised needs: - In this stage, the above formalized needs are transformed into a formal system such as direct contact with the librarian, sources, services or the system. In this process the librarian should be knowledgeable about "The subject of the seekers" interests" "Their motivation" "Personal characteristics of the users" "The relationship of the inquiry to file organization" and "Anticipated answer". Taylor identified this process as five filters of the question negotiation between the user and the librarian.

When considering the above four types of needs, they focused the existing knowledge levels of the users. The users with formalized needs want directions about the information system. When they come to the compromised stage, the direct support of the librarian should start. Three stages such as visceral, conscious, and formalized needs focus on the levels of needs of the users when they seek information by themselves. But when the users come to the stage of compromise needs, system help or direct support of the librarian will be needed. Taylor basically pointed out the essentials of understanding the nature of the information needs stages of the users through four levels of needs occurrences while explaining more 
widely how the five filters are used to negotiate questions with the librarian at the compromised stage.

\section{Needs as a gap in knowledge}

If the individual knowledge structure and the life structure are unable to fulfill the required information needs, failure creates a gap between the needs and the users (Allen, 1996). This gap occurs because of the perception or the lack of knowledge (Schema activation), identification of alternative action (Slot filling) and the selection of alternative courses of action (Action - consequence /ink). It is based on the variation gap of the individual knowledge structure and the life situation. That variation is the failure of the required knowledge. In other words, he pointed out that the individual's knowledge is directly influenced by the users' life structure. The extent of both pieces of knowledge and life structure leads to understanding the gaps between the information needs required of the user's knowledge and the levels of the anomaly of the state knowledge.

\section{Gaps through sense making process}

A search for information begins with making sense of the information needs situation. It is defined as, "sense making approach" (Dervin, 1990). Sensemaking explores three elements such as a situation in time and space, which defines the context in which information problems arise; a gap between the contextual situation and the desired situation (e.g. uncertainty and outcome) which is the consequence of the gap between situation and outcome. Dervin presented these elements in terms of a triangle as a situation, a gap/bridge, and outcome. She proposed an information needs situation as the user being unable to make sense of it and the decision making coming to a halt. She further named the decision - making as a movement of needs. This movement is prevented from those gaps. To 
minimize these gaps, one must create a new sense to make progress. Here, the sense must be actively constructed.

According to this theory, there are bridges to cross the above gaps. Her arguments are based on two distinct approaches such as human thoughts and actions on information which exist independently. Then it posses an inherent order that can be identified and manipulated. While describing the sense - making process, she considered information as a theoretical object under three different perspectives.

1. Information represents many forms of necessity for humans which is external to the self. This information could be obtained from the environment and also from the formal sources which are available in a required field. This situation makes sense of outside impact of the information needs.

2. She pointed out the users who have their own ideas about their wants. These situations represent the contributions of the individual ability towards gaining the needed information. Every person has their own reality. If the first and the second situations of the information cannot be resolved by the required information or reality, then the third information situation will have to be employed.

3. In the third situation, the users have to make sense of decisions on what kind of solutions they should apply to fill the gaps which are coming from the second information situation. They should consult people in the field or they can rely on the information systems and retrieval to fill their information problems.

She viewed those three kinds of perspectives as a situation in space and time. The users with a lack of required information have to construct a desirable relationship between the space and time in the aforesaid situation. The three information situations are the way of finding alternatives 
to search for information with available knowledge of the above - mentioned two situations

The users have to make sense and take decisions with the knowledge of the context in which information problems may arise. These cognitive statuses of humans are a continual process in time and space. The level of knowledge decides the position of the users. This level always supports and has the capability of making sense within itself. Background or the outside environment where the person is, provides an additional supportive role for sense making.

\section{Need as uncertainty through common process approach}

In the information behavior context, the information is subjective, created by users through the process of interpretation and discovery of meaning which is something objective existing outside the users (Kuhlthau, 1991-2004). Her views imply that the experience of the user is a key component. She also tried to understand the psychological processes of the user to construct a sense of their needs for information.

She further discussed that information seeking is as a contextualized process of constructing and understanding from an initial state of uncertainty. Seeking patterns is based on the needs that associate with the search process and the actions of seeking and using sources. It incorporates with three major components such as the affective (Feeling), the cognition (Thoughts), and the physical search (Actions and strategies). These components are common in each stage of the search process. Basically her views are based on the information seeker's experience. These are introduced as a Task initiation, Topic selection, Preliminary exploration, Focus formulation, Information collection, Search closure and writing. She further mentioned that the users are directly involved in solving their needs situations while seeking. Therefore, factors such as the state of the user's needs, use of sources and the ways of searching are all dynamic. 
This is how her six stages were activated in the sense making process. When the users need some information, perhaps they may not know what kinds of information are needed for their problems. It may be due to ignorance of their knowledge. Then they feel that they want information to solve the problem or task and create to initiate a search. Having initiated the task, the users are trying to select the topic which is relevant to their information needs. Those topics help them to explore the investigation that they might predict through the exploration; perhaps the users might get more complicated information on particular needs. But they may be rather busy with locating the relevant documents or may have lack of sense in finding more appropriate documents.

Each stage is affected by sense and the anxiety of the users. But still, the problem remains. The users have to forecast or judge their real needs but are unable to find the most relevant information which they are looking for. Then the users have to focus a formulation on this stage about the information which they want and they should be able to reduce the uncertainty they have had so far. In this stage their sense of their own confidence will be increased. The focus formulation is equal to the formalized needs of Taylor's arguments. Now the users' level of uncertainty is growing less and less. They feel much more confident of collecting what they need. Under the next closer stage of search, Kuhlthau pointed out that the users' searching ability by themselves is through the system or with the help of the librarian. The final stage is presenting, writing or achieving the information by closing the entire process. If the users are still not satisfied with the outcome, then another anomaly or uncertainty may grow. Each of the stages of the sense making process expressed the users' confidence and lack of confidence, satisfaction and dissatisfaction.

When we look at Kuhlthau's explanation, it is well proven that each stage of her six levels of users' information seeking process links with her basic principles of feeling, thoughts and actions. Each of the principles is affected 
with uncertainty. If the users were able to construct certainty through the entire process, the expected information needs could be sorted out easily.

Kunlthau's paradigms emphasized that peoples' information needs are something real rather than experimentally determined information problems. She explored the relationship of uncertainty with the users' perception of the complexity of task, formulation of focus and use of sources by studying the behavior of school children in 1983 and securities in 1993. At the beginning, both of the studies identified uncertainty as a perception of a person which is influenced by the workplace.

\section{Needs as a stress}

Sometimes, the user is satisfied or dissatisfied with the previously acquired information. This situation propels the users into a cluster of activities for searching for what they want. Wilson's models of information behavior revealed how information needs arise and what are the intervening variables affected with the user (Wilson, 1981, 1996). He focused on:

1. Information needs and its drivers and the factors that give rise to an individual's perception of needs.

2. The factors that affect the individual's response to the perception of needs;

3. The processes or actions involved in that response

To identify the environment of the users, the life situation of their perceptions and activities are important in the information need situations. In the 1981 model, he included the context of information needs as personal, social role of the person and the environment which the user represents. But the revised model in 1996 introduced two types of activating mechanism in this process such as stress and coping which could affect the 
needs directly. He defined it as a link between needs and action. Stress is the status of a person which is directly influenced by kinds of intervening variables such as psychological, demographical, interpersonal and environmental factors which favor the user's information needs occurrences. He generally introduced these variables as the context influences.

\section{Need as antecedent factor}

Johnson (1997) has presented a model with seven factors under three headings such as Antecedents, Information carrier factors and Information seeking action. The first factor has two internal categories; background factors and personal relevance factors. He defined the background factor as demographic and direct experience of the user. It is quite reasonable to assume that the experienced user may have more familiarity than the new user. Evaluating the user's direct experience is too complex. But it is a necessary requirement for modeling the information needs, because the entire process can be altered through this direct experience.

Under the personal relevance factors, he further pointed out the two factors; salience and belief. He considered belief to be the topic of the subject and the salience as the information about the topic. These two personal relevance factors represent the user's degree of knowledge. It is very important because belief constrains the user's level of motivation on seeking information.

According to the literature findings, it is obvious that the cognitive knowledge structure which is influenced by users' surroundings makes the information needs situations. The essays discussed have focused especially on the impact of cognitive variabies on information needs occurrences from different angles. This situation expressed in various ways and terms in the above discussion such as a process of question negotiation (Taylor, 1962-1968), Perception or gap of knowledge (Allen, 
1996), Making sense (Dervin, 1982-1992), As a stress (Wilson, 1981,1996), As an antecedent factor (Johnson, 1997), As a process of uncertainty (Kuhlthau, 1991). Even though it is not discussed in detail, some have pointed it as a knowledge surrogate (Farradane, 1976), Need as a structure (Thomson, 1968), Reducing uncertainty (Belkin, 1976, 1978, 1982, 1985), As an event (Pratt, 1977), As sensory awareness (Chew, 1994) or in terms of an anomaly in the user's state of knowledge (Atkin, 1973).

Information needs through complex dimension "paucity of total intellectual power and influence of socio backgrounds"

The variables related with the process of information needs occurrences have become more complicated aspect and dragged the attention of the scholars through different avenues as mentioned above. In this paper, a new dimension is added while it is recognized as a complex situation created by the paucity areas of the users' current states of knowledge. Throughout the discussion, a number of scholars have revealed knowledge differences through different angles. Based on the results of the discussion, it is identified that there are void areas in the stages of the individual's knowledge (one who can't find any particular answer by him/herself) when a question arises. The problem of insufficient knowledge occurred due to a variety of voids that have appeared in the current state of the knowledge areas. (The term, "voids occur due to paucity" used in this paper is identified in different ways through the above discussion such as gaps, stress, anomaly, uncertainty, sense maker, antecedents, answers for question etc.) The concept of paucity encompasses the different characteristics of the individual which are described in the model later. Several indications of high cognitive factors will be involved to create voids in the process because the users have to perform and maintain very complex mental processes at different stages on information needs occurrences. The expected information needs can be provided easily if the above-mentioned variables of the information seekers are identified. 
Basically the users start seeking information owing to the lack of sufficient information which they really need. Then, users must use their individual capacity to achieve the target information. In this situation, some specific cognitive factors such as the skills factors or the intelligence, psychological factors or the confidence and the knowledge factors or the experience of the overall intellectual power increase or decrease the degree of insufficient needs. But the combination of each factor could vary from person to person. Some individuals are better than others.

Why is the cognitive factor important in information needs occurrences? Because information needs is a very discrete complex situation of the information system. In addition to intellectual capacity, variables of the socio backgrounds of the user cause some influences on their intellectual capacity and increased or reduced complexity. Therefore, in this context, two basic environments which are influenced the users have been identified as follows. The inner circle in the diagram (Figure: 01) represents the cognitive environment while the outer circle represents the socio environment. Each of the environments includes three grounds of the cognitive factors and the socio influences of the user. Based upon the recognition of each assumption, the following dimension is used to represent the hidden characteristics considering information needs occurrences beginning from the very complex situation of the individual knowledge structure which is influenced by the socio factors.

Figure: 01 - Presents the socio - cognitive relationship.

The information needs occurrences as a complex situation of the user owing to the paucity of total intellectual power of the cognitive factors and the impact of the socio environment which the user represents. The sociocognitive perspectives represent relation of the socio environment on a personal knowledge. 
ternal Factors (Socio environment)

Internal Factors (Cognitive environment)

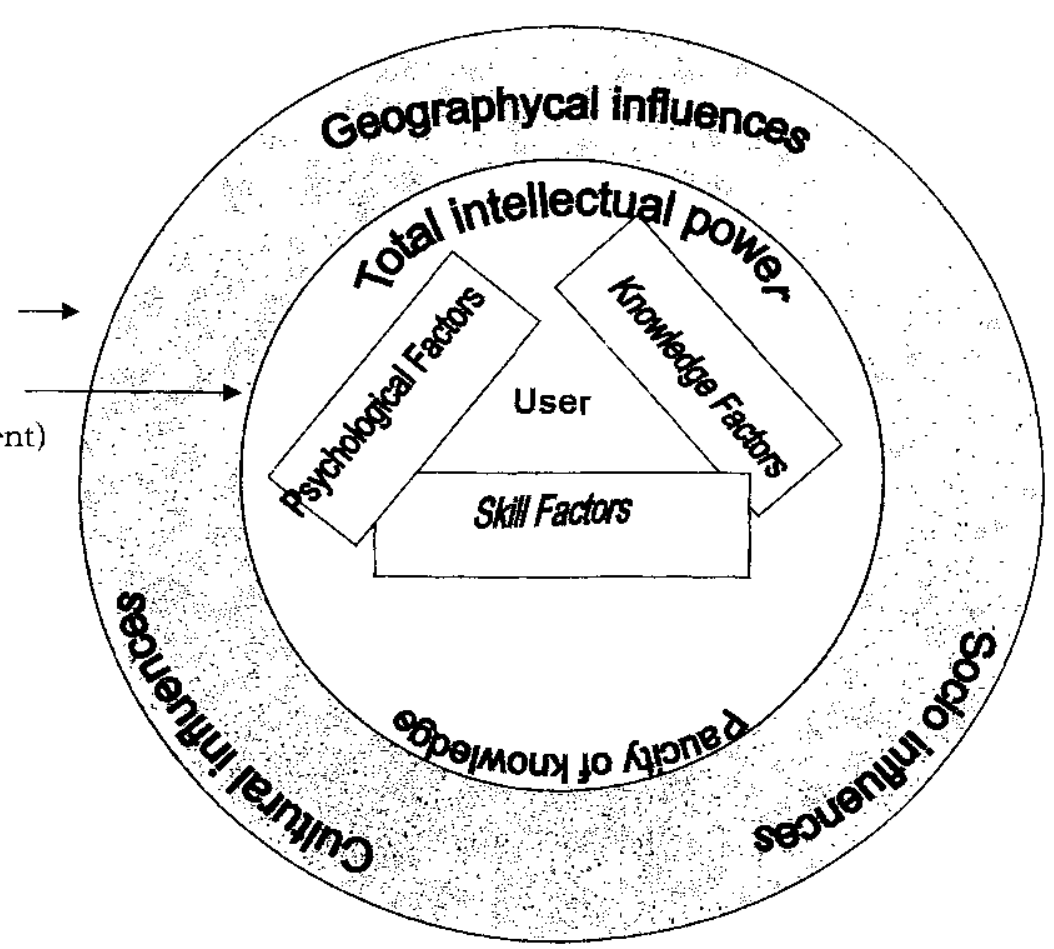

Some selected variables and stages of the information needs occurrences

Information needs are always taking place, everywhere in society. It may be common to any kind of community. The following hypothetical general model represents the basic variables and stages of information needs occurrences that could be applied to different kinds of communities. The model says a direct relationship exists among the users' information needs. It has been introduced as the pre-intervening variables of the user. The process of pre-intervening variables identifying the information needs occurrences begins with the complex situation created by some paucity areas of the user's knowledge. That complexity may arise due to two kinds 
of basic factors such as internal (cognitive) and external (socio) factors. A cognitive variable is a set of features which expresses the individual's knowledge identity and capacity. These cognitive activities have significant relation with the various aspects of the socio environment such as socio, cultural, and geographical infuences that the user represents.

The information needs occurrences always concern the use of identification of the affected variables of that process. When identifying the information needs occurrences, it is needed to have a better understanding of both of the environments of the users. These concerns are essential especially in designing both a self - help and an intermediate user service. Those are: pre- intervening variables of the user in the socio-cognitive context which initially introduced earlier and basic stages of the information needs occurrences. It should be noted that, apart from its own prediction, the proposed hypothetical model has many cross links and bypass routes with previous studies. The model is mapped in rather a systematic way with the above findings and it provides a basic knowledge of each stage of the information needs occurrences with brief descriptions (Figure: 02). 

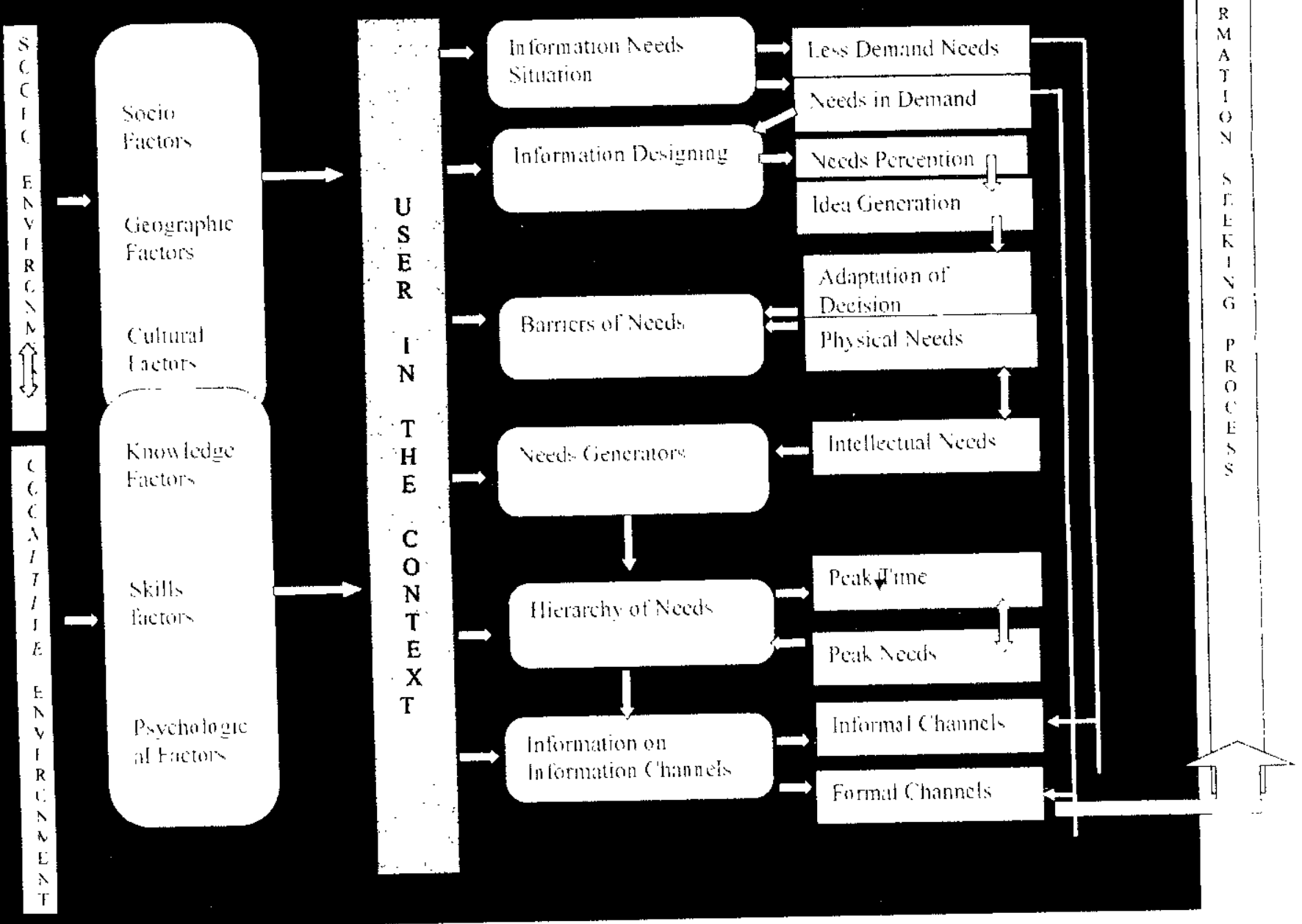


\section{Pre-intervening variables - cognitive environment (internal factors)}

The characteristics which represent the internal factors fall into three main categories as follows:

\section{Knowledge factors:}

The knowledge factor could be identified as the interpersonal capability which is related to need experience, usage of the required needs or familiarity with the needs. These factors may represent the individual's direct knowledge (experience) and indirect knowledge (personal ability) of the desired needs. When information needs emerge, the users have to obtain a steady and exact idea about the needs. They have to set their own limits and boundaries for information needs and should be capable of raising questions with themselves on what information, how, when and where it can be found. An experienced user knows clearly about the needed information at least to some extent. Therefore, the experience is work as a key selector in this process. This direct knowledge or experience can be obtained through seminars, exhibitions, use of libraries, source familiarity, and knowledge of subject areas, and from personal contacts.

Indirect or personal ability is a kind of detective capability of understanding the required needs using their own intelligence and judgments. In this stage, users who haven't direct experience that can't find exact boundaries about their needs, can judge something of the needed information by themselves.

\section{Skill factors:}

Even though the user has experience, the function of the array of skills of the users such as language skill, logical skill and technical skill may be affected. It can be used and grouped as ability to communicate, capability to interview with a librarian or others, negotiation skills, ability to analyze the 
available needs, being comfortable with technologies etc. It directly increases or reduces the information needs occurrences. Even though these variables seem to be very effective in dynamic needs, it is essential to understand the logical mind of the users when they want statistical needs also. If any- one has less ability to cope with the needs through his/her skill power; others may be par excellence for the same. Therefore, the skill factors of the user are directly affected by the needs occurrences.

\section{Impact of psychological factors:}

When information is needed, early on there will be a conflict in one's mind with a series of questions such as what, where, how and when. This complicated situation creates a favorable psychological state. This state includes self-confidence, enthusiasm, patience, perseverance, imagination, willingness or interest, curiosity, flexibility, frustration, happiness, phobia, belief, success and values etc. These psychological variables are the, "outlook on life structure" of the individuals.

Why are the psychological variables so important in information needs occurrences? Information needs is a kind of detailed reflection of mental reaction. Need is an invisible output of the total mentality. Throughout this paper, some have identified these variables as feelings of the user.

Pre -intervening variables- socio environment (External factors)

Both users and information needs are an adaptive system. The information needs of the user will reflect characteristics largely on the outer environment other than the cognitive environment which has been discussed briefly earlier. The characteristics which represent the external variables also fall into three categories. Those are socio factors, geographic locations, and cultural differences of the user. 


\section{Socio factors of the user.}

For formulation of information needs, socio factors of the users are greatly affected. Most information needs start with the nature of the users which they represent. It may differ on the basis of demographic differences such as children, young adults or older citizens, students or professionals and on gender.

\section{Geographic locations:}

This may be area differences, (geographic locations), staff differences, (in an organization), or class differences, (in a coliege or year deference in a university). It is obvious that the needs of the information and the levels of the individual's behavior may differ between rural and urban areas. Therefore, the geographic location could be considered as a major external variable on information needs occurrences.

\section{Cultural differences:}

Impact of cultural mediation on information needs is another external variable that could be seen. It includes national, regional, racial or religious factors.

\section{Basic stages of need occurrences}

Informetion needs situations or the types of needs predicted:

The type of information needs situations, even though they appeared in different terminology throughout the findings, articulate the user's information necessity. It has been proven that the demanded needs situation tends to involve search strategies. The entire information seeking process based on these types of needs requires a detailed examination. 
When examining the information needs differences in the groups of people throughout this study, it is found that basically two types of information needs occurred.

The first type of information needs do not set out "seek strategies". These needs are obtained from the sources of newspapers, colleagues, supervisors, friends and other informal channels in day-to-day life. This consumption has been found in different terminology such as kinetic needs, current or every day needs, express needs, application needs, immediate needs, short term needs and self extension needs etc...(Table: 01).

The second set of needs which have contextual values enable the user to use a cluster of activities to find relevant needs such as potential needs, exhaustive needs, latent needs, nutritional needs, deferred needs, long term needs, and intellectual needs. In this aspect, the users expect more dynamic ways of finding those needs such as formal or semi formal channels(Table:01).

Table: 01 Presents the comparison of information needs identifications

\begin{tabular}{|l|l|l|}
\hline Interpreter & Needs in less demand(First set) & Needs in demand (Second set) \\
\hline Childer -1975 & Kinetic need & Potential need \\
\hline Vogit -1961 & Current or every day need & Exhaustive need \\
\hline Lancaster - 1979 & Express need & Latent need \\
\hline Mick -1980 & Application need & Nutritional need \\
\hline Kirkelas -1983 & Immediate need & Deferred need \\
\hline Taylor - 1968 & Short term need & Long term need \\
\hline Dunn - 1986 & Self extension need & Intellectual need \\
\hline
\end{tabular}




\section{Information dasigning:}

Having identified whether there is a demand for the required information, then the user has to design the needs in a particular way such as need perception, idea generation and adaptation of the decision according to the demand. Need perception could include fast needs, wide needs and deep needs depending on the nature of the problem or task perception. Then it will lead to the creation of some idea about the information horizon, sources and media where the information is available. Finally that idea helps in reaching a decision as to what to do or where to go.

\section{Affected barriars in the process:}

There are also barriers such as physical needs (construction of available information) such as information needs about the information retrieval systems and intellectual needs, (the way of using those constructs needs) to be identified or the inside information of the information system.

\section{Information naads generators:}

The next significant stage is the information needs generators. It could be expressed through different tasks performed by the user. It may be frequencies of personal needs, work or task oriented and academic needs. For example, undergraduates in different academic classification may have different needs generators such as research work, class work, term papers, assignments, writing papers, etc...

\section{Hierarchy of naeds:}

These needs generators create a hierarchy of needs according to the nature of the task involved. The peak need at peak time affects the needs hierarchy. It sets a relationship between the user and the hierarchy. This hierarchy typically depends upon the nature of the needs or the interest in 
the subject and the task performed by the user. This kind of information needs sets users to select specific needs events or set priorities for information seeking.

\section{Channels and communications (Information needs on ways of access)}

This hierarchy of needs influences the user to choose channels, such as formal, semi-formal and informal, depending on the levels of the information needs. The hierarchy decides the suitable channel as a part of the information-seeking process. The information channels are the key facilitator or broker existing between the information needs and the information-seeking of the entire process. At this stage, the information of the information channels and the links of the information sources with those channels pertaining to the required needs must be known.

\section{Conclusion}

The aim of this paper has been to cover a few selected user studies to understand the grounds, concepts and approaches, with particular regard to the cognitive phenomenon on information needs occurrences. It directed us to think of users' available knowledge structure and their imaginable power of information. The cognitive metaphor implies a place for emotion of information needs as a complex object. The hypothetical model also firmly included the characteristics and behaviors of human cognition and is focused on how, when and why information needs occurred until the process of searching begins.

This paper suggests that information needs is not a single discrete event or a single instant. It is a dynamic process of complex situations involving the user, created by paucity of knowledge. In this aspect, the information needs occurrences have been analyzed by a variety of user studies. These studies presented different concepts, methods and models. The selected studies used for the discussion of this paper develop the amalgamated 
models which represent information needs and information seeking behaviors together. But the overall aim of this study is to discuss the selected research literature related to information needs in order to create a clear picture of it. Throughout the literature search, it was found that the studies on the topic in the research field are very common and very extensive. Therefore, the review was limited to only a few more relevant studies by grouping them as cognitive perspectives and their views of the needs studies.

This paper is used to explain the existing phenomena for presenting a prediction. Finally, different theoretical perspectives were used for the discussion and those were unified to design the prediction which is presented through a comprehensive model. The importance of studying the characteristics of information needs aimed at throughout this paper facilitates the initiation and implementation of both self-help and intimated library systems. The Library system requires a new conceptualized information system to function with the complexity of the user and the environment. Therefore this study attempts to reveal the most relevant broader and deeper views of information needs studies. These observations provide a comprehensive overview of the past and the present developments in this field. 


\section{References}

Allen, L.B. (1996) Information task: towards a user-centered approach to information systems, San Diego: CA: Academic Press, pp.56.

Atkin, C. (1973) "Instrumental utilities and information seeking in new models for Mass Communication research, ed. Peter Clarke, Sage Annual Reviews of Communication Research, Vol.2. Beverly Hills: Sage, pp.205242.

Barbara, N.A. (2003) "Proposed general model of information behavior" Information Research. Vol. No. 1. Accessed 22.03.2006, at:http://informationr.net/ir/91/paper 164.html.

Belkin, N. (1978) "Information concept for information science" Journa/ of Documentation. Vol.39 pp. 55-85.

Chew, F. (1992) "Information needs during viewing of serious and routine news". Journal of Broadcasting and Electronic Media, 36(4)453-466

Childers, T. (1975) The information-poor in America. Metuchen; Scarecrow Press,

Dervin, B. and Nilan, M. (1986) "Information needs and users", In: Williams Martha ed. Annual Review of Information Sciences and Technology, Vol. 21. Knowledge Industry Publication, pp.333.

Dervin, B. (1990) "From the mind's eye of the user: the sense making qualitative- quantitative methodology" Qualitative Research in Information Management, Englewood: Libraries Unlimited, pp.61-84.

Dunn, K. (1986) "Psychological needs and source linkage in undergraduate information seeking behavior" College and Research Libraries. Vol.47.pp. $475-481$. 
Farradane, J. (1976) Information Scientist. Vol.10, pp.91-101. Fishenden, R.M. (1965) "Information use studies, part 1: past result and future needs", The Journal of Documentation, 21 (September 1965) pp.163-168.

Hayden, K.A. (2000) Information seeking mode/s: EDC/ 701. Calgary: University of Calgary, Accessed 03.03.2006, at:

http:www.ucalgary.org.hayden.htm.

Jhonson, J.D. (1997) Cancer related information seeking, Cresskill: NJ:Hampton Press, pp.239.

Kristine, T. (1998) Information Seeking, Retrieving, Reading, and Storing Behavior of Library - Users, 64th IFLA General Conference August 16- August 21

Kirkelas, J. (1983) "Information - seeking behaviors: patterns and concepts" Drexel library quarterly, 19 No. pp.20-25.

Kuhlthau, C.C. (1991) "Inside the search process: information seeking from the user's perspective", Journal of the American Society for Information Science, vol.42 No.5,pp.361-371.

Kuhlthau, C.C. (2004) Seeking Meaning: a process approach to hibrary and information services, WestPoint: Libraries Unlimited.

Kuhlthau, C.C. Information Search Process: a search for meaning rather than answer.

Accessed,02.03.2006, at:http://www.scils.rutgers.edu/ -kuhlthau/search $\% 20$ Process. html.

Lancaster, F.W. (1979) Information retrieval systems: characteristics, testing and evaluation. New York: Jhon Wily. 
Mick, C.K., Lindsy, G.N., \& Callahan, D. (1980) "Toward usable user studies" Journal of

American Society for Information Science, Vol, 33.pp.347-356

Pratt, A.D. (1977) "The information of the image" Libri. Vol, 27.pp. 204-220.

Nazan, O.U. Information needs and seeking behaviors of scholars at a Turkish university. Accessed 15.03.2006, at:

http://www.ifla.org/IV/fila64/041-112e.htm.

Rowely, J.F. \&Turner, C.N.D. (1978) The Dissemination of Information, London: Andre Deutsch, pp.54.

Taylor, R.S. (1968) "Question negotiation and Information seeking in libraries." College and Research Libraries, Vol.29. pp. 178-194.

Taylor, R.S. (1991) "Information use environments" Frogress in Communication Sciences, Vol.X, pp. 217-255

Thompson, F.B. (1968) "The organization of the image" American Documentation Vol.19, pp.305-308.

Vakkarai, P. (1997) Information seeking in context proceedings of an internationa/ conference on research in information needs, seeking and use in different context 14-16 August, 1996 Tampere: Finland.

Vogit, M.J. (1961) Scientist approaches to information, Chicago: ALA

Wilson, T.D. (1981) "On user studies and information needs" Accessed 05.02.2006, at:http:/informationr.net/tdw/publ/papers/1981 infoneeds.htmi. 
Wilson, T.D. (1999) "Models in Information Behavior Research" The Journal of Documentation, Vol. 55. No. 3. pp.249-270.

Wilson, T.D.(1997) "Information Behavior: an interdiscipiinary perspectives" Information Processing Management, Vol. 33, No. 4. pp.551-572.

Wilson, T.D. (2000) "Human Information Behavior" Informing Science, Vol. 3, No. 2. pp.49-56 Accessed 07.02.2006, at http://informationr.net/tdw/pub1/papers/1981

Wilson, T.D. (1994) Information needs and uses: Fifty years of progress? Accessed 09.03.2006, at: http://informationr.net/tdw/pub1/p 